\title{
Comparación entre la normativa peruana y la normativa Extranjera relacionada a la durabilidad del concreto
}

Comparison between Peruvian regulations and foreign regulations related to the durability of the concrete

Paula Nicole Dongo Gómez, Orlando Javier Saavedra Pérez, Dania Lisset Espinoza Huaquisto

Universidad Católica de Santa María. Arequipa Perú.

\section{INFORMACIÓN}

\section{Historia del Artículo}

Recepción: 14/03/2019

Revisión: 15/06/2019

Aceptación: 20/06/2019

\section{Palabras Clave}

Durabilidad, normas técnicas,

concreto, exposición.

\section{Key Words}

Durability, technical standards, concrete, exposure.

\section{DOI}

https://doi.org/10.35286/veritas. v20i1.228

\begin{abstract}
RESUMEN
En la presente investigación se realizó una comparación entre las normas peruana, estadounidense, argentina, boliviana y brasilera de concreto estructural, con el fin de analizar su contenido respecto a la durabilidad del concreto y encontrar posibles falencias de la normativa peruana vigente. La durabilidad del concreto es la capacidad que tiene este material de soportar la acción de diversos agentes que modifican sus propiedades. Este aspecto ha adquirido importancia en los últimos años debido a que su consideración en el diseño de estructuras podría prevenir problemas como agrietamiento, corrosión, carbonatación y otros, los cuales podrían poner en riesgo la funcionalidad de construcciones vitales en la sociedad, además de causar gastos por reparación y en los peores casos, reconstrucción. Para elaborar un concreto durable se hace un análisis del tipo de exposición en el que se encontrará la estructura proyectada, de modo que se puedan tomar medidas que atenúen efectos negativos sobre esta. Las normas consultadas consideran diversos parámetros para cada tipo de exposición, las cuales tienen diversa nomenclatura. Algunos de los parámetros encontrados son: resistencia a la compresión del concreto, relación agua/cemento, tipo de cemento, profundidad de penetración y velocidad de absorción. Los datos encontrados en las normas analizadas son congruentes entre sí, en algunos casos, son los mismos; esto se debe a que algunas normas han sido elaboradas en base a la norma estadounidense. Se hallaron también parámetros propios de cada país, siendo uno de los casos el ensayo de profundidad de penetración al agua, reglamentado únicamente en Argentina.
\end{abstract}

\begin{abstract}
In the present investigation, a comparison was made between the Peruvian, Argentine, Bolivian and Brazilian standards of structural concrete, in order to analyze its content regarding the durability of the concrete and find possible shortcomings of the current Peruvian legislation. The durability of concrete is the ability of this material to withstand the action of various agents that modify its properties. This aspect has become important in recent years because its consideration in the design of structures could prevent problems such as cracking, corrosion, carbonation and others, which could put at risk the functionality of vital constructions in society, besides causing costs for repair and in the worst cases, reconstruction. To make a durable concrete, an analysis of the type of exposure in which the projected structure will be found is made, so that measures can be taken to mitigate negative effects on it. The consulted standards consider different parameters for each type of exposure, which have different nomenclature. Some of the parameters found are: compressive strength of the concrete, water/ cement ratio, type of cement, depth of penetration and absorption speed. The data found in the analyzed standards are congruent with each other, in some cases, they are the same; this is because some standards have been developed based on the US standard. We also found parameters specific to each country, being one of these cases the water penetration depth test, regulated only in Argentina.
\end{abstract}

\section{INTRODUCCIÓN}

Los diferentes tipos de estructuras de concreto construidas actualmente, demandan la imposición de parámetros mínimos que garanticen su seguridad frente a cualquier evento, es por ello que múltiples normativas han sido elaboradas en base a investigaciones para conseguirlo.

La durabilidad del concreto es uno de los parámetros predominantes para lograr que las estructuras de este material cumplan con la vida útil para la cual fueron proyectadas.

Correspondencia:

Paula Nicole Dongo Gómez

paulanicole33@gmail.com
Esta está ligada a distintos factores tales como procesos constructivos, calidad de materiales y permeabilidad. Para estos dos últimos se cuentan con distintos ensayos para determinarlos.

Según la norma Comité ACI 318 (2014) la permeabilidad, llamada así a la capacidad que tiene el concreto de permitir el paso de diferentes sustancias en estado líquido y gaseoso, es el principal factor que debe ser considerado en el diseño de mezclas de concreto.

A pesar de ser una propiedad esencial del concreto, la permeabilidad no es tomada en cuenta para su elaboración; los profesionales encargados del diseño, consideran únicamente la resistencia a la compresión como parámetro de diseño. La normatividad peruana carece de especificaciones que 
permitan saber qué condiciones debe cumplir un concreto respecto a su permeabilidad para ser aceptado, tampoco menciona rangos aceptables ni procesos constructivos relacionados a dicha propiedad. Por otro lado, estudios en España, Colombia, Argentina y Argelia demuestran que la permeabilidad y el ensayo utilizado para su obtención, deben ser considerados en el diseño de estructuras vulnerables según el grado de exposición en el que se encuentren.

Es por eso que esta parte del proyecto de investigación se centrará en comparar la normativa peruana con la extranjera, recomendando acotaciones relacionadas a la durabilidad dadas en las distintas normas revisadas para su posible incorporación a la normativa peruana.

\section{Objetivos}

Realizar la comparación de las recomendaciones referidas a la durabilidad en el diseño del concreto encontradas en las normas peruana y extranjeras.

\section{Desarrollo}

\section{Comparación de aspectos considerados en las diferentes} normas técnicas

A continuación, se mostrará una compilación de tablas encontradas en las diferentes normas, se procederá a colorear del mismo color las celdas que presenten información similar.

\section{Condiciones o clases de exposición}

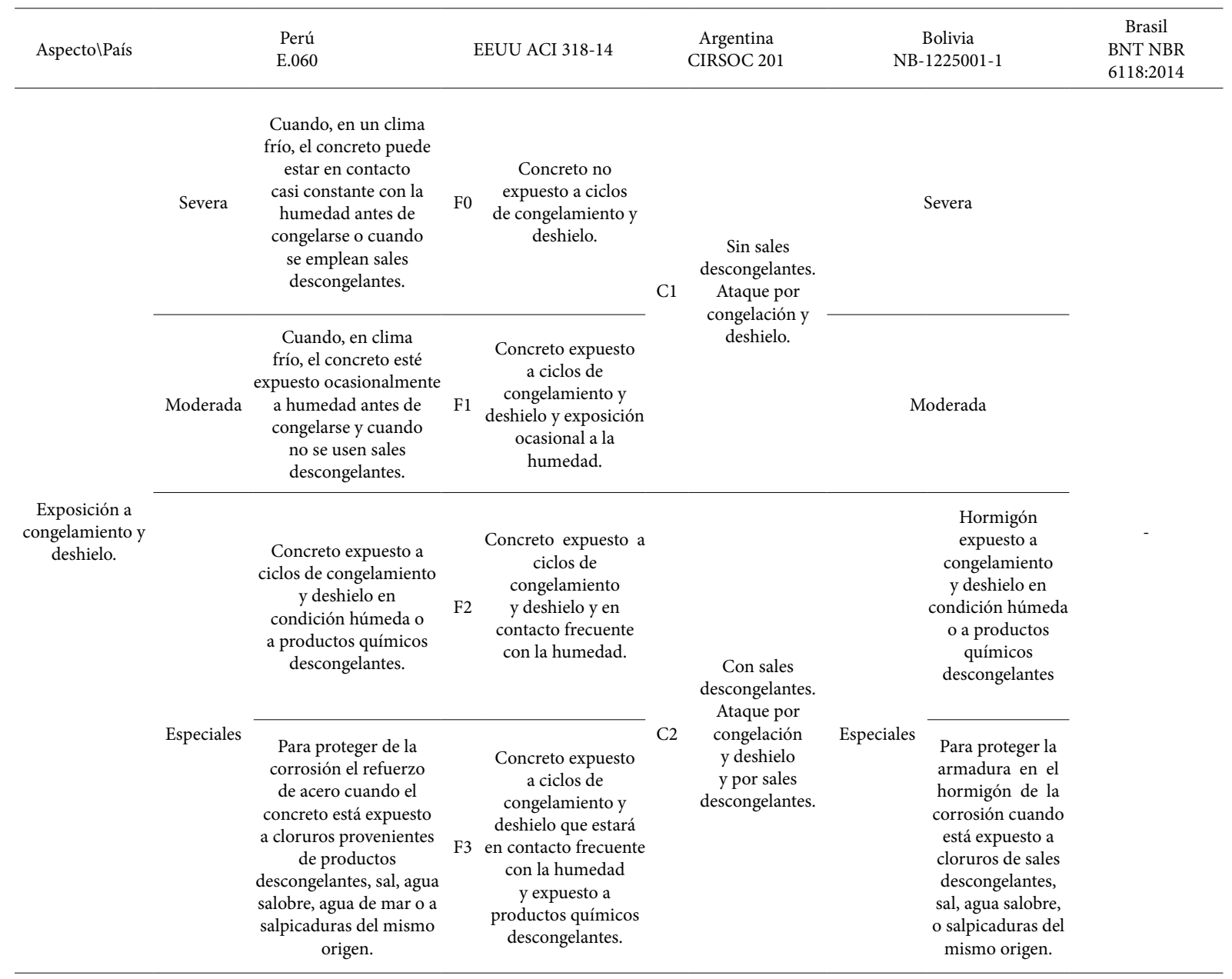


VÉRITAS Vol. 20 N¹ (2019) 65-81

\begin{tabular}{|c|c|c|c|c|c|c|c|c|c|}
\hline Aspecto $\backslash$ País & $\begin{array}{l}\text { Perú } \\
\text { E.060 }\end{array}$ & \multicolumn{2}{|c|}{ EEUU ACI 318-14 } & \multicolumn{2}{|c|}{$\begin{array}{c}\text { Argentina } \\
\text { CIRSOC } 201\end{array}$} & \multicolumn{3}{|c|}{$\begin{array}{c}\text { Bolivia } \\
\text { NB-1225001-1 }\end{array}$} & $\begin{array}{c}\text { Brasil } \\
\text { BNT NBR } \\
6118: 2014\end{array}$ \\
\hline \multirow{8}{*}{$\begin{array}{l}\text { Exposición a } \\
\text { sulfatos. }\end{array}$} & \multirow{4}{*}{$\begin{array}{c}\text { * Sulfato soluble } \\
\text { en agua } \\
\text { (SO4) } \\
\text { presente } \\
\text { en el suelo, } \\
\text { porcentaje en } \\
\text { peso. }\end{array}$} & Insignificante & $\begin{array}{c}0,0 \leq \mathrm{SO} 4 \\
<0,1\end{array}$ & \multicolumn{2}{|c|}{$\begin{array}{l}{ }^{*} \text { Sulfatos solubles (SO4) en aguas } \\
\text { de contacto. mg/litro. }\end{array}$} & \multirow{4}{*}{$\begin{array}{c}\text { * Sulfato } \\
\text { Acuosoluble } \\
\text { (SO4) en } \\
\text {-suelo, porcentaje } \\
\text { en peso. }\end{array}$} & Insignificante & $\begin{array}{c}0,0 \leq \\
\mathrm{SO} 4< \\
0,1 .\end{array}$ & \multirow{8}{*}{-} \\
\hline & & Moderada & $\begin{array}{c}0,1 \leq \mathrm{SO} 4 \\
<0,2\end{array}$ & $\begin{array}{l}\text { Moderado } \\
\text { (Q1) }\end{array}$ & 150 a 1500. & & Moderada & $\begin{array}{l}0,1 \leq \\
\mathrm{SO} 4< \\
0,2 \text { o } \\
\text { agua } \\
\text { de mar. }\end{array}$ & \\
\hline & & Severa & $\begin{array}{c}0,2 \leq \mathrm{SO} 4 \\
<2,0\end{array}$ & Fuerte (Q2) & 1500 a 10000 & & Severa & $\begin{array}{c}0,2 \leq \\
\mathrm{SO} 4< \\
2,0 .\end{array}$ & \\
\hline & & Muy severa & $2,0<\mathrm{SO} 4$ & $\begin{array}{l}\text { Muy fuerte } \\
\text { (Q3) }\end{array}$ & Mayor a 10000. & & Muy severa & $\begin{array}{l}2,0< \\
\mathrm{SO} 4\end{array}$ & \\
\hline & \multirow{4}{*}{$\begin{array}{c}\text { * Sulfato (SO4) } \\
\text { en el agua, } \\
\text { ppm. }\end{array}$} & Insignificante & $\begin{array}{c}0 \leq \mathrm{SO} 4< \\
\quad 150\end{array}$ & $\begin{array}{r}\text { * Sulfatos sol } \\
\mathrm{d} e \\
\%\end{array}$ & $\begin{array}{l}\text { les ( } \mathrm{SO} 4) \text { en suelos } \\
\text { ontacto. } \\
\text { masa. }\end{array}$ & \multirow{4}{*}{$\begin{array}{l}{ }^{*} \text { Sulfato }(\mathrm{SO} 4) \\
\text { en el agua, } \mathrm{ppm} .\end{array}$} & Insignificante & $\begin{array}{c}0 \leq \\
\mathrm{SO} 4< \\
150 .\end{array}$ & \\
\hline & & Moderada & $\begin{array}{c}150 \leq \mathrm{SO} 4 \\
<1500 \text { o } \\
\text { agua marina. }\end{array}$ & $\begin{array}{l}\text { Moderado } \\
\text { (Q1) }\end{array}$ & 0,10 a 0,20 & & Moderada & $\begin{array}{l}\mathrm{SO} 4< \\
0,2 \quad \text { o } \\
\text { agua } \\
\text { de mar. }\end{array}$ & \\
\hline & & Severa & $\begin{array}{c}1500 \leq \\
\mathrm{SO} 4< \\
10000 .\end{array}$ & Fuerte (Q2) & 0,20 a 2 & & Severa & $\begin{array}{c}0,2 \leq \\
\mathrm{SO} 4< \\
2,0 .\end{array}$ & \\
\hline & & Muy severa & $\begin{array}{c}10000< \\
\text { SO4. }\end{array}$ & $\begin{array}{l}\text { Muy fuerte } \\
\text { (Q3) }\end{array}$ & Mayor a 2. & & Muy severa & $\begin{array}{c}2,0< \\
\mathrm{SO} 4\end{array}$ & \\
\hline
\end{tabular}

\begin{tabular}{|c|c|c|c|c|c|c|}
\hline Aspecto\País & $\begin{array}{l}\text { Perú } \\
\text { E.060 }\end{array}$ & & EEUU ACI 318-14 & $\begin{array}{c}\text { Argentina } \\
\text { CIRSOC } 201\end{array}$ & $\begin{array}{c}\text { Bolivia } \\
\text { NB-1225001-1 }\end{array}$ & $\begin{array}{c}\text { Brasil } \\
\text { BNT NBR 6118:2014 }\end{array}$ \\
\hline En contacto con el agua. & $\begin{array}{l}\text { Concreto que se } \\
\text { pretende tenga baja } \\
\text { permeabilidad en } \\
\text { exposición al agua. }\end{array}$ & W0 & $\begin{array}{c}\text { Concreto seco } \\
\text { en servicio o concreto } \\
\text { en contacto con el agua } \\
\text { donde no se requiere baja } \\
\text { permeabilidad. } \\
\begin{array}{c}\text { En contacto con el agua } \\
\text { donde se requiera baja } \\
\text { permeabilidad. }\end{array}\end{array}$ & - & $\begin{array}{l}\text { Hormigón que se } \\
\text { pretende tenga baja } \\
\text { permeabilidad en } \\
\text { exposición al agua. }\end{array}$ & - \\
\hline
\end{tabular}

\begin{tabular}{|c|c|c|c|c|c|c|c|c|}
\hline Aspecto \País & $\begin{array}{c}\text { Perú } \\
\text { E.060 }\end{array}$ & & UU ACI 318-14 & & & $\begin{array}{c}\text { Argentina } \\
\text { CIRSOC } 201\end{array}$ & $\begin{array}{c}\text { Bolivia } \\
\text { NB-1225001-1 }\end{array}$ & $\begin{array}{c}\text { Brasil } \\
\text { BNT NBR } \\
\text { H6118:2014 }\end{array}$ \\
\hline \multirow{2}{*}{$\begin{array}{l}\text { Riesgo de } \\
\text { corrosión. }\end{array}$} & \multirow[t]{2}{*}{ - } & $\mathrm{C} 0$ & $\begin{array}{l}\text { Concreto seco o } \\
\text { protegido } \\
\text { contra la } \\
\text { humedad. }\end{array}$ & $\begin{array}{l}\text { * Corrosión por } \\
\text { carbonatación. }\end{array}$ & $\mathrm{A} 2$ & $\begin{array}{l}\text { Ambiente normal. } \\
\text { Interiores de edificios expuestos al aire } \\
\text { con } \mathrm{HR} \geq \\
65 \% \text { o a condensaciones; } \\
\text { exteriores expuestos a lluvias con } \\
\text { precipitación media anual }<1000 \mathrm{~mm} \text {; } \\
\text { elementos } \\
\text { enterrados en suelos húmedos o sumergidos. }\end{array}$ & - & - \\
\hline & & $\mathrm{C} 1$ & $\begin{array}{l}\text { Concreto expuesto } \\
\text { a la humedad, } \\
\text { pero no a una } \\
\text { fuente externa } \\
\text { de cloruros. }\end{array}$ & $\begin{array}{l}\text { Corrosión por } \\
\text { carbonatación. }\end{array}$ & $\mathrm{A} 3$ & $\begin{array}{c}\text { Exteriores } \\
\text { expuestos a lluvias con precipitación media } \\
\text { anual } \geq 1000 \mathrm{~mm} \text {; temperatura media } \\
\text { mensual durante más de } 3 \text { meses al año } \\
\geq 25^{\circ} \mathrm{C} .\end{array}$ & & \\
\hline
\end{tabular}


Dongo Gómez et al. / VÉRITAS Vol. 20 №1 (2019) 65-81

\begin{tabular}{|c|c|c|c|c|c|c|c|c|}
\hline Aspecto\País & $\begin{array}{l}\text { Perú } \\
\text { E.060 }\end{array}$ & & EEUU ACI 318-14 & & & $\begin{array}{l}\text { Argentina } \\
\text { CIRSOC } 201\end{array}$ & $\begin{array}{c}\text { Bolivia } \\
\text { NB-1225001-1 }\end{array}$ & $\begin{array}{c}\text { Brasil } \\
\text { BNT NBR } \\
6118: 2014\end{array}$ \\
\hline \multirow{5}{*}{$\begin{array}{l}\text { Riesgo de } \\
\text { corrosión. }\end{array}$} & \multirow{5}{*}{-} & \multirow{5}{*}{$\mathrm{C} 2$} & \multirow{5}{*}{$\begin{array}{l}\text { Concreto expuesto a } \\
\text { la humedad y a una } \\
\text { fuente externa de } \\
\text { cloruros provenientes } \\
\text { de productos químicos } \\
\text { descongelantes, sal, } \\
\text { agua salobre, agua de mar } \\
\text { o salpicaduras del mismo } \\
\text { origen. }\end{array}$} & $\begin{array}{l}\text { * Corrosión } \\
\text { por cloruros. }\end{array}$ & $\mathrm{CL}$ & $\begin{array}{l}\text { Húmedo o } \\
\text { sumergido, con cloruros de origen dife- } \\
\text { rente del medio marino. Hormigón expuesto } \\
\text { al rociado o la fluctuación del nivel de agua } \\
\text { con cloruros; expuesto a aguas naturales } \\
\text { contaminadas por desagües industriales. }\end{array}$ & \multirow[t]{5}{*}{ 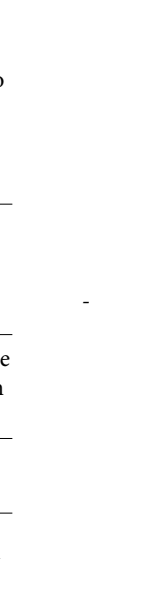 } & \multirow{5}{*}{ - } \\
\hline & & & & & MI & $\begin{array}{l}\text { Marino, al aire. A más de } 1 \mathrm{~km} \text {. de la línea } \\
\text { de marea alta y contacto eventual con aire } \\
\text { saturado de sales. }\end{array}$ & & \\
\hline & & & & \multirow{3}{*}{$\begin{array}{l}\text { Corrosión } \\
\text { por cloruros. }\end{array}$} & \multirow[t]{2}{*}{ M2 } & $\begin{array}{l}\text { Marino, al aire. A menos de } 1 \mathrm{~km} \text {. de la línea de } \\
\text { marea alta y contacto perman. o frecuente con } \\
\text { aire saturado con sales. }\end{array}$ & & \\
\hline & & & & & & $\begin{array}{c}\text { Sumergidos en agua de mar, por debajo del } \\
\text { nivel mínimo de mareas. }\end{array}$ & & \\
\hline & & & & & M3 & $\begin{array}{l}\text { Marino, sumergido. En la zona de fluctuación } \\
\text { de mareas o expuesto a salpicaduras del mar. }\end{array}$ & & \\
\hline
\end{tabular}

\begin{tabular}{|c|c|c|c|c|c|c|c|}
\hline Aspecto $\backslash$ País & $\begin{array}{l}\text { Perú } \\
\text { E.060 }\end{array}$ & $\begin{array}{l}\text { EEUU ACI } \\
318-14\end{array}$ & \multicolumn{2}{|r|}{$\begin{array}{l}\text { Argentina } \\
\text { CIRSOC } 201\end{array}$} & $\begin{array}{c}\text { Bolivia } \\
\text { NB-1225001-1 }\end{array}$ & \multicolumn{2}{|c|}{$\begin{array}{c}\text { Brasil } \\
\text { BNT NBR 6118:2014 }\end{array}$} \\
\hline & & & Al & $\begin{array}{l}\text { No agresiva. Interiores } \\
\text { de edificios no sometidos a condensaciones; } \\
\text { elementos exteriores de edificios, revestidos; } \\
\text { hormigón masivo interior; estructuras en } \\
\text { ambientes rurales y climas desérticos, con } \\
\text { precipitación media anual }<250 \mathrm{~mm} \text {. }\end{array}$ & & I & Débil. \\
\hline & & & Q1 & $\begin{array}{c}\text { Ambientes con } \\
\text { agresividad química moderada. Suelos, } \\
\text { aguas o ambientes que contienen elementos } \\
\text { químicos capaces de provocar la alteración } \\
\text { del hormigón con velocidad. }\end{array}$ & & II & Moderada. \\
\hline \multirow[t]{3}{*}{$\begin{array}{c}\text { Agresividad ambiental y/o } \\
\text { General. }\end{array}$} & - & - & & & - & & \\
\hline & & & Q2 & $\begin{array}{c}\text { Ambientes con } \\
\text { agresividad química fuerte. Suelos, aguas } \\
\text { o ambientes que contienen elementos } \\
\text { químicos capaces de provocar la alteración } \\
\text { del hormigón con velocidad media; } \\
\text { exposición al agua de mar. }\end{array}$ & & III & Fuerte \\
\hline & & & Q3 & $\begin{array}{c}\text { Ambientes con } \\
\text { agresividad química muy fuerte. Suelos, } \\
\text { aguas o ambientes que contienen elementos } \\
\text { químicos capaces de provocar la alteración } \\
\text { del hormigón con velocidad rápida. }\end{array}$ & & IV & Muy Fuerte \\
\hline
\end{tabular}


VÉRITAS Vol. 20 N¹ (2019) 65-81

Requerimientos para el concreto para las diferentes condiciones de exposición a congelamiento y deshielo.

\begin{tabular}{|c|c|c|c|c|c|c|c|c|c|}
\hline Aspecto $\backslash$ País & $\begin{array}{l}\text { Perú } \\
\text { E.060 }\end{array}$ & & EEUU ACI 318-14 & $\begin{array}{r}\text { Arg } \\
\text { CIRS }\end{array}$ & $\begin{array}{l}\text { atina } \\
\text { C } 201\end{array}$ & & $\begin{array}{c}\text { Bolivia } \\
\text { NB-1225001- }\end{array}$ & & $\begin{array}{c}\text { Brasil } \\
\text { BNT NBR } \\
6118: 2014\end{array}$ \\
\hline $\begin{array}{l}\text { Disposiciones } \\
\text { generales. }\end{array}$ & $\begin{array}{l}\text { Los concretos de peso normal } \\
\text { pesos livianos expuestos a cond } \\
\text { congelamiento y deshielo o a p } \\
\text { químicos descongelantes deben } \\
\text { incorporado, con el contenido } \\
\text { aire indicado en la tabla ubica } \\
\text { La tolerancia en el contenido } \\
\text { aire incorporado debe ser de } \pm \\
\text { concretos con f'c mayor de } 35 \mathrm{MI} \\
\text { reducir el aire incorporado indi } \\
\text { tabla antes mencionada en }\end{array}$ & $\begin{array}{l}\text { los de } \\
\text { iones de } \\
\text { oductos } \\
\text { ener aire } \\
\text { otal de } \\
\text { a abajo. } \\
\text { otal de } \\
5 \% \text {. Para } \\
\text {, se puede } \\
\text { ado en la } \\
1 \% \text {. }\end{array}$ & $\begin{array}{c}\text { El concreto de peso normal y } \\
\text { liviano expuesto } \\
\text { a congelamiento y deshielo } \\
\text { clasificado en las Clases de } \\
\text { Exposición F1, F2 o F3 debe tener } \\
\text { aire incorporado. } \\
\text { El concreto debe muestrearse de } \\
\text { acuerdo con ASTM C172, y el } \\
\text { contenido de aire debe medirse } \\
\text { de acuerdo con ASTM C231 o } \\
\text { ASTM C173. } \\
\text { Para valores de f'c que excedan } \\
5000 \text { lb. } \\
\text { /pulg.2, se permite la reducción } \\
\text { del contenido de aire en } 1.0 \text { punto } \\
\text { de porcentaje indicado en la tabla } \\
\text { ubicada abajo. } \\
\text { El máximo porcentaje de } \\
\text { puzolanas, incluida la ceniza } \\
\text { volante, humo de sílice y cemento } \\
\text { de escoria en concreto } \\
\text { asignado a Exposición Clase F3, } \\
\text { debe estar de acuerdo con los } \\
\text { valores mostrados más abajo. }\end{array}$ & $\begin{array}{r}\text { Debe incorporar } \\
\text { aire, en la cantic } \\
\text { tabla ubica } \\
\text { Para hormigon } \\
\text { mayo } \\
35 \text { (f'c=35 MF } \\
\text { de aire indi } \\
\text { anteriorment } \\
\text { pueden reducir } \\
\text { porcentual }(1,0 \\
\text { Documentos de } \\
\text { lo co } \\
\end{array}$ & $\begin{array}{l}\text { intencio } \\
\text { d requer } \\
\text { a más ab } \\
\text { de clase } \\
\text { zue H- } \\
\text { las ca } \\
\text { das en la } \\
\text { nencion } \\
\text { asta una } \\
\text {, salvo q } \\
\text { oyecto s } \\
\text { rario. }\end{array}$ & $\begin{array}{l}\text { almente } \\
\text { da en la } \\
\text { jo. } \\
\text { igual o } \\
\text { tidades } \\
\text { tabla } \\
\text { da, se } \\
\text { unidad } \\
\text { le en los } \\
\text { indique }\end{array}$ & $\begin{array}{r}\text { El hormigón de peso } \\
\text { y de peso liviano exp } \\
\text { condiciones de congela } \\
\text { y deshielo o a produ } \\
\text { químicos descongelant } \\
\text { tener aire incorporado } \\
\text { contenido de aire indi } \\
\text { la tabla ubicada más at } \\
\text { tolerancia en el conter } \\
\text { aire incorporado debe } \\
1,5 \% \text {. Para un } \mathrm{f} \\
>35 \mathrm{MPa} \text {, se puede re } \\
\text { aire incorporado indica } \\
\text { tabla anteriormente mer } \\
\text { en } 1 \% .\end{array}$ & $\begin{array}{l}\text { normal } \\
\text { uesto a } \\
\text { amiento } \\
\text { actos } \\
\text { es, debe } \\
\text {, con el } \\
\text { cado en } \\
\text { bajo. La } \\
\text { hido de } \\
\text { ser de } \pm \\
\text { c } \\
\text { ducir el } \\
\text { ado en la } \\
\text { ncionada }\end{array}$ & - \\
\hline \multirow{4}{*}{$\begin{array}{c}\text { Relación máxima } \\
\mathrm{a} / \mathrm{mc} .\end{array}$} & $\begin{array}{l}\text { Concreto expuesto a } \\
\text { ciclos de congelamiento } \\
\text { y deshielo en condición } \\
\text { húmeda o a productos } \\
\text { químicos descongelantes }\end{array}$ & \multirow[t]{2}{*}{0.45} & F0 & \begin{tabular}{c} 
Tipo de \\
hormigón\} \backslash $\\
{\text { Cond. de }} \\
{\text { exposición }}$ & $\mathrm{C} 1$ & $\mathrm{C} 2$ & $\begin{array}{l}\text { Hormigón } \\
\text { expuesto a } \\
\text { congelamiento } \\
\text { y deshielo en } \\
\text { condición húmeda } \\
\text { o a productos } \\
\text { químicos } \\
\text { descongelantes. }\end{array}$ & 0.45 & \multirow{4}{*}{ - } \\
\hline & \multirow{3}{*}{$\begin{array}{c}\text { Para proteger de la } \\
\text { corrosión el refuerzo de } \\
\text { acero cuando el concreto } \\
\text { está expuesto a cloruros } \\
\text { provenientes de productos } \\
\text { descongelantes, sal, agua } \\
\text { salobre, agua de mar o a } \\
\text { salpicaduras del mismo } \\
\text { origen. }\end{array}$} & & 0.55 & $\begin{array}{l}\text { Hormigón } \\
\text { simple }\end{array}$ & 0.45 & 0.40 & \multirow{3}{*}{$\begin{array}{l}\text { Para proteger el } \\
\text { armadura en el } \\
\text { hormigón de la } \\
\text { corrosión cuando } \\
\text { está expuesto a } \\
\text { cloruros de sales } \\
\text { descongelantes, } \\
\text { sal, agua salobre, } \\
\text { o salpicaduras del } \\
\text { mismo origen. }\end{array}$} & \multirow[t]{3}{*}{0.40} & \\
\hline & & \multirow{2}{*}{0.40} & 0.45 & $\begin{array}{c}\text { Hormigón } \\
\text { armado }\end{array}$ & 0.45 & 0.40 & & & \\
\hline & & & 0.40 & $\begin{array}{l}\text { Hormigón } \\
\text { pretensado }\end{array}$ & 0.45 & 0.40 & & & \\
\hline
\end{tabular}
\end{tabular}


Dongo Gómez et al. / VÉRITAS Vol. 20 №1 (2019) 65-81

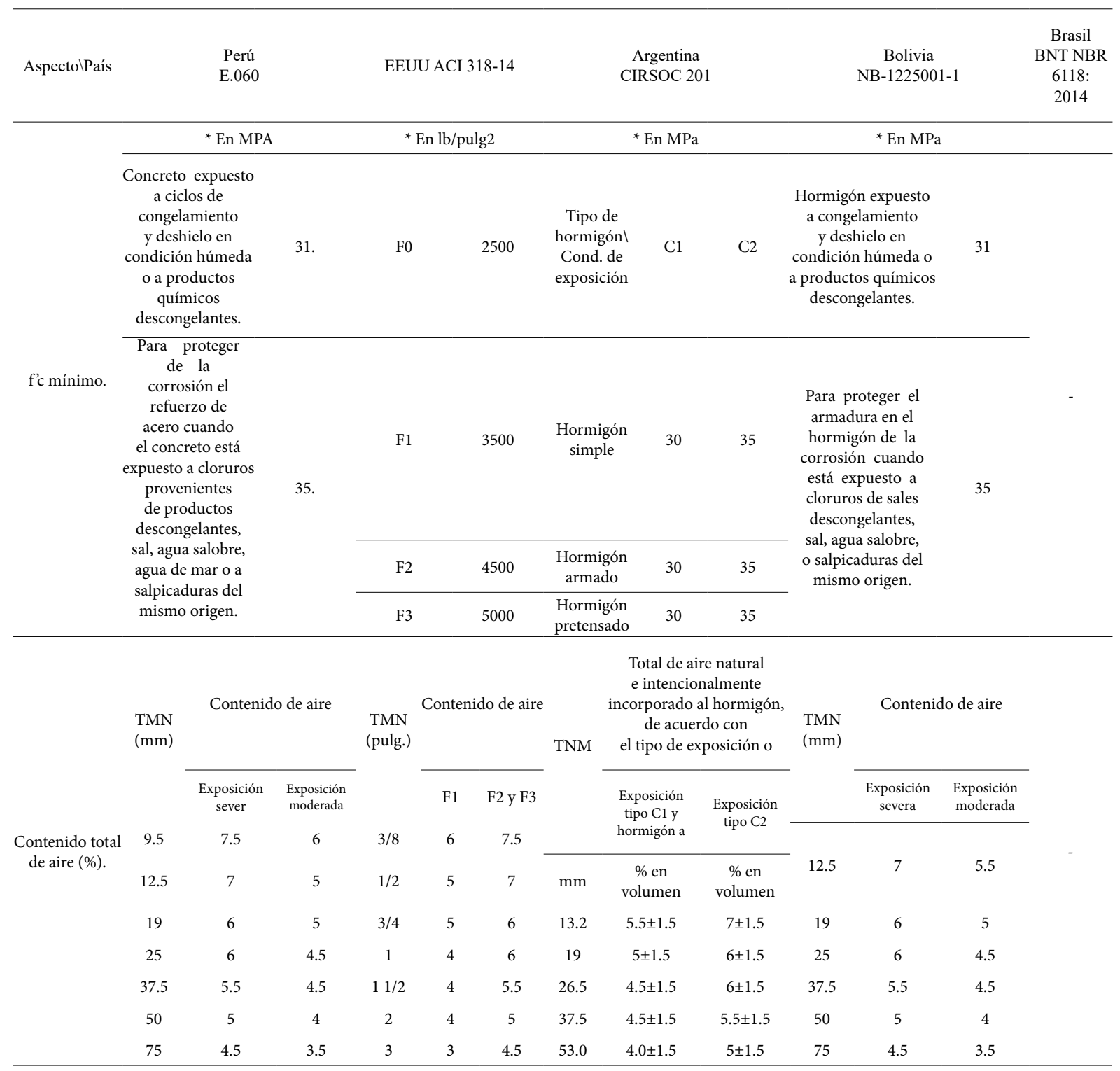


VÉRITAS Vol. 20 N¹ (2019) 65-81

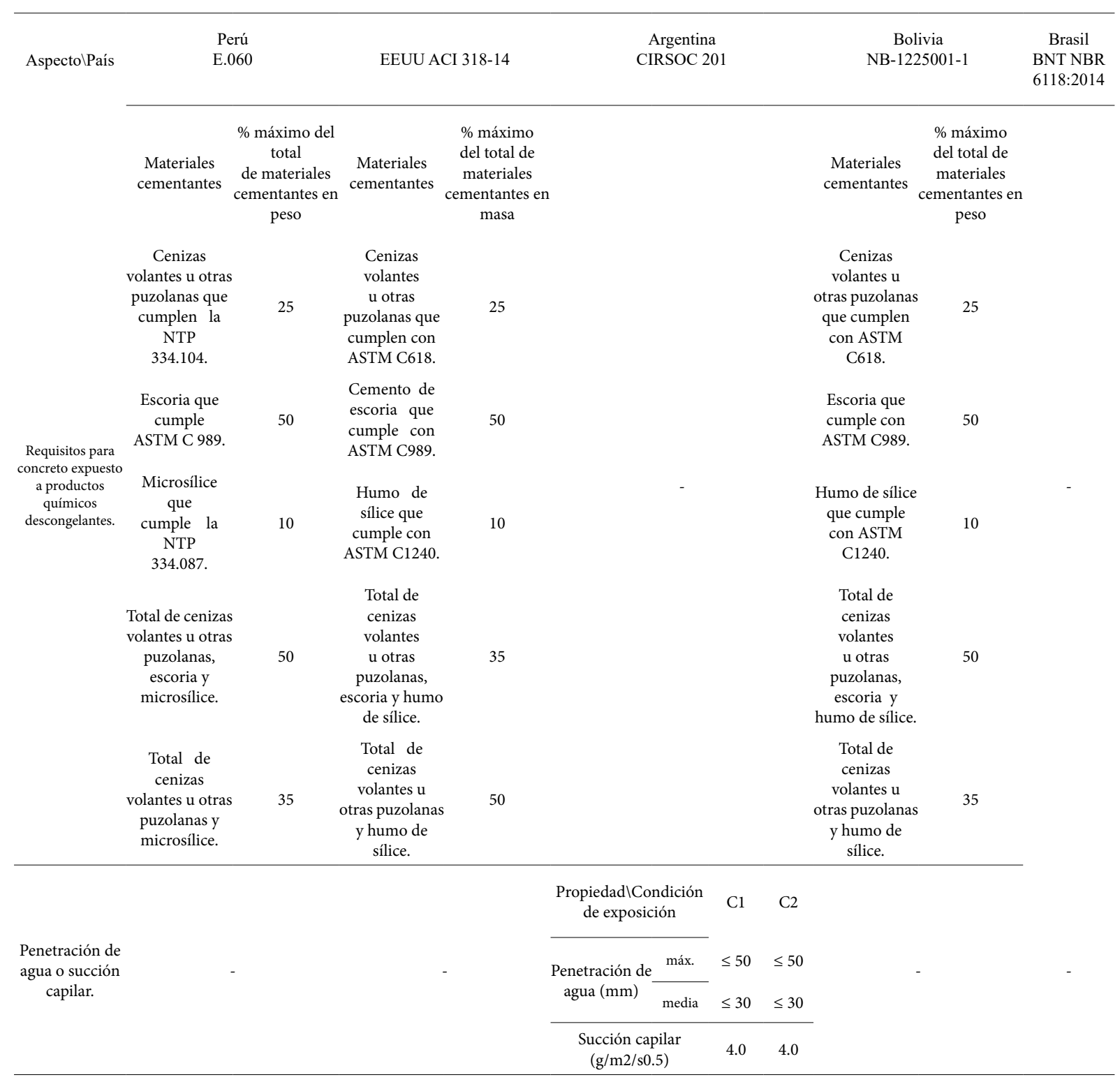


Dongo Gómez et al. / VÉRITAS Vol. 20 N¹ (2019) 65-81

Requerimientos para el concreto para las diferentes condiciones de exposición a sulfatos

\begin{tabular}{|c|c|c|c|c|c|}
\hline Aspecto $\backslash$ País & $\begin{array}{l}\text { Perú } \\
\text { E.060 }\end{array}$ & EEUU ACI 318-14 & $\begin{array}{c}\text { Argentina } \\
\text { CIRSOC } 201\end{array}$ & $\begin{array}{c}\text { Bolivia } \\
\text { NB-1225001-1 }\end{array}$ & $\begin{array}{c}\text { Brasil } \\
\text { BNT NBR } \\
\text { 6118:2014 }\end{array}$ \\
\hline
\end{tabular}

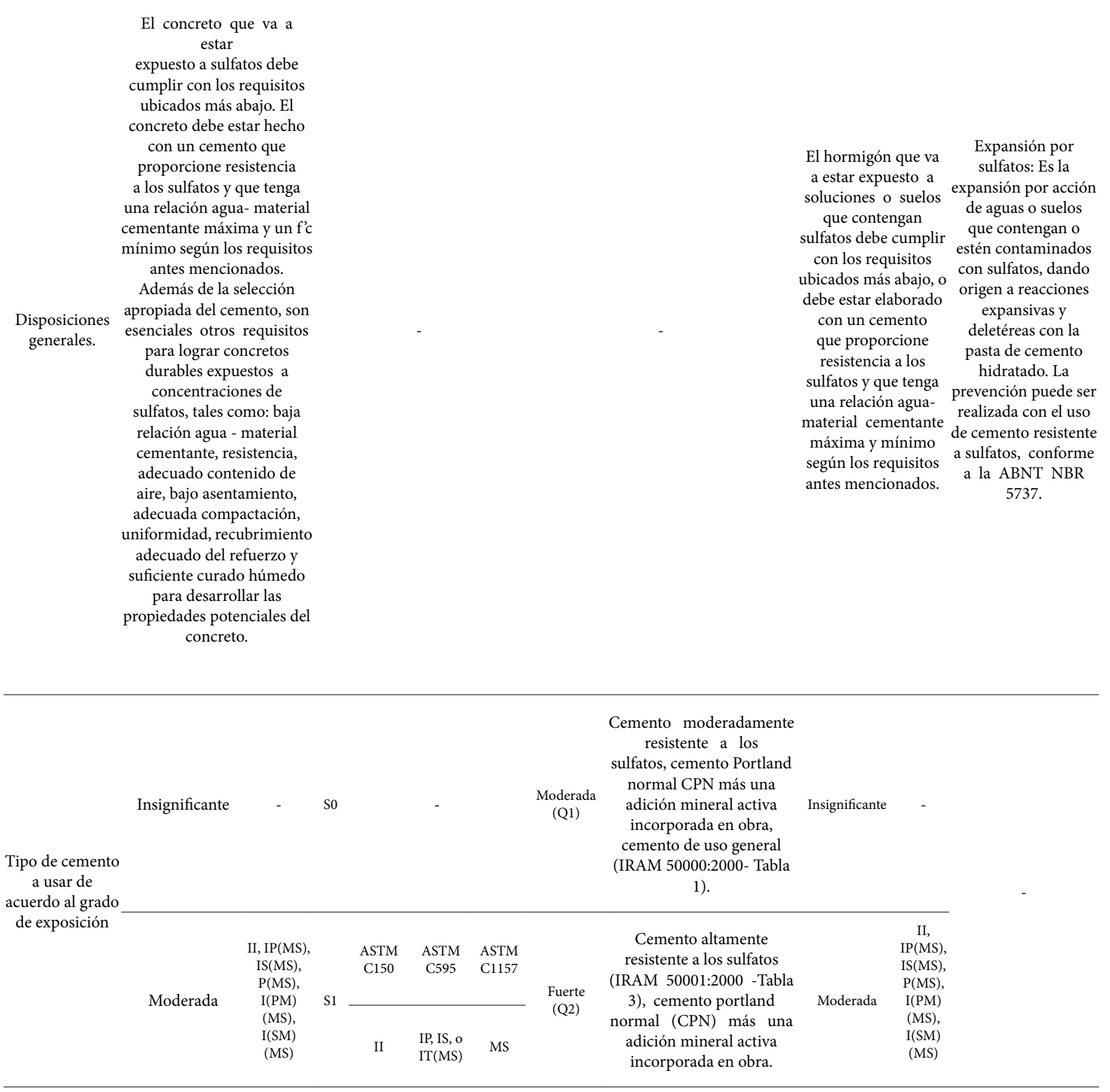


VÉRITAS Vol. 20 N¹ (2019) 65-81

\begin{tabular}{|c|c|c|c|c|c|c|c|c|c|c|c|c|c|}
\hline Aspecto\País & \multicolumn{2}{|c|}{$\begin{array}{l}\text { Perú } \\
\text { E.060 }\end{array}$} & \multicolumn{4}{|c|}{ EEUU ACI 318-14 } & \multicolumn{4}{|c|}{$\begin{array}{c}\text { Argentina } \\
\text { CIRSOC } 201\end{array}$} & \multicolumn{2}{|c|}{$\begin{array}{c}\text { Bolivia } \\
\text { NB-1225001-1 }\end{array}$} & $\begin{array}{c}\text { Brasil } \\
\text { BNT NBR } \\
\text { 6118:2014 }\end{array}$ \\
\hline \multirow[b]{2}{*}{$\begin{array}{l}\text { Tipo de } \\
\text { cemento a usar } \\
\text { de acuerdo } \\
\text { al grado de } \\
\text { exposición. }\end{array}$} & Severa & V & S2 & V & $\begin{array}{l}\text { IP, IS o } \\
\text { IT(HS) }\end{array}$ & HS & & \multirow{2}{*}{\multicolumn{3}{|c|}{$\begin{array}{c}\text { Cemento con adiciones altamente } \\
\text { resistente a } \\
\text { los sulfatos (IRAM } \\
\text { 50001:2000-Tabla 3). El contenido } \\
\text { de cemento del hormigón será } \\
\text { igual o mayor que } 380 \mathrm{~kg} / \mathrm{m} 3 \text {, } \\
\text { cemento sin adiciones altamente } \\
\text { resistente a los sulfatos (CPN- } \\
\text { ARS- IRAM } 50001: 2000-\text { Tabla 3) } \\
\text { utilizado conjuntamente con una } \\
\text { adición mineral activa agregada } \\
\text { en obra. La adición debe mejorar } \\
\text { la resistencia a los sulfatos del } \\
\text { cemento. El contenido de material } \\
\text { cementicio del hormigón será } \\
\text { igual o mayor que } 380 \mathrm{~kg} / \mathrm{m} 3 \text {, } \\
\text { Cemento altamente resistente a } \\
\text { los sulfatos (CPN ARS- IRAM } \\
50001: 2000-\text { Tabla } 3 \text { y yna } \\
\text { protección exterior capaz de } \\
\text { resistir la agresión. El contenido de } \\
\text { cemento del hormigón será igual o } \\
\text { mayor que } 350 \mathrm{~kg} / \mathrm{m} 3 \text {. }\end{array}$}} & Severa & V & \\
\hline & Muy severa & $\begin{array}{l}\text { Tipo V más } \\
\text { puzolana }\end{array}$ & S3 & $\begin{array}{l}\text { V más } \\
\text { puzolanas o } \\
\text { cemento } \\
\text { de escoria }\end{array}$ & $\begin{array}{l}\text { IP, IS o } \\
\text { IT(HS) más } \\
\text { puzolanas o } \\
\text { escoria }\end{array}$ & $\begin{array}{l}\text { HS más } \\
\text { puzolanas o } \\
\text { escoria. }\end{array}$ & $\begin{array}{l}\text { Muy fuerte } \\
\text { (Q3) }\end{array}$ & & & & Muy severa & $\begin{array}{l}\text { V más } \\
\text { puzolana }\end{array}$ & - \\
\hline \multirow{5}{*}{$\begin{array}{c}\text { Relación } \\
\text { máxima a/mc. }\end{array}$} & Insignificante & - & So & & - & & \begin{tabular}{c} 
Tipo de \\
hormigón\} $\\
{\text { Cond. de }} \\
{\text { exposición }}$ & $\begin{array}{l}\text { Moderada } \\
\text { (Q1) }\end{array}$ & $\begin{array}{c}\text { Fuerte } \\
\text { (Q2) }\end{array}$ & $\begin{array}{c}\text { Muy } \\
\text { fuerte } \\
\text { (Q3) }\end{array}$ & Insignificante & - & \multirow{9}{*}{ - } \\
\hline & Moderada & 0.50 & S1 & & 0.50 & & $\begin{array}{l}\text { Hormigón } \\
\text { simple }\end{array}$ & 0.50 & 0.45 & 0.40 & Moderada & 0.50 & \\
\hline & Severa & 0.45 & S2 & & 0.45 & & $\begin{array}{l}\text { Hormigón } \\
\text { armado }\end{array}$ & 050 & 0.45 & 0.40 & Severa & 0.45 & \\
\hline & Muy severa & 0.45 & S3 & & 0.45 & & $\begin{array}{l}\text { Hormigón } \\
\text { pretensado }\end{array}$ & 0.50 & 0.45 & 0.40 & Muy severa & 0.45 & \\
\hline & ${ }^{*}$ En $N$ & & & & En lb/pulg2 & & & ${ }^{*} \mathrm{En} \mathrm{MP}$ & & & ${ }^{*}$ En & MPa & \\
\hline \multirow{4}{*}{ f'c mínimo } & Insignificante & - & So & & 2500 & & \begin{tabular}{c} 
Tipo de \\
hormigón\} $\\
{\text { Cond. de }} \\
{\text { exposición }}$ & $\begin{array}{l}\text { Moderada } \\
\text { (Q1) }\end{array}$ & $\begin{array}{l}\text { Fuerte } \\
\text { (Q2) }\end{array}$ & $\begin{array}{c}\text { Muy } \\
\text { fuerte } \\
\text { (Q3) }\end{array}$ & Insignificante & - & \\
\hline & Moderada & 28 & S1 & & 3500 & & $\begin{array}{l}\text { Hormigón } \\
\text { simple }\end{array}$ & 30 & 35 & 40 & Moderada & 28 & \\
\hline & Severa & 31 & S2 & & 4500 & & $\begin{array}{l}\text { Hormigón } \\
\text { armado }\end{array}$ & 30 & 35 & 40 & Severa & 31 & \\
\hline & Muy severa & 31 & S3 & & 5000 & & $\begin{array}{l}\text { Hormigón } \\
\text { pretensado }\end{array}$ & 35 & 40 & 45 & Muy severa & 31 & \\
\hline \multirow{4}{*}{$\begin{array}{l}\text { Aditivo } \\
\text { cloruro de } \\
\text { calcio }\end{array}$} & Insignificante & - & So & & Sin restricción & & & & & & Insignificante & - & \\
\hline & Moderada & - & S1 & & Sin restricción & & & & & & Moderada & - & \\
\hline & Severa & $\begin{array}{l}\text { No se } \\
\text { permite }\end{array}$ & S2 & & No se permite & & & - & & & Severa & No se permite & - \\
\hline & Muy severa & $\begin{array}{l}\text { No se } \\
\text { permite }\end{array}$ & S3 & & No se permite & & & & & & Muy severa & No se permite & \\
\hline
\end{tabular}
\end{tabular}
\end{tabular}


Dongo Gómez et al. / VÉRITAS Vol. 20 №1 (2019) 65-81

\begin{tabular}{|c|c|c|c|c|c|c|c|c|}
\hline Aspecto \País & $\begin{array}{l}\text { Perú } \\
\text { E.060 }\end{array}$ & $\begin{array}{l}\text { EEUU } \\
\text { ACI } \\
318-14\end{array}$ & & $\begin{array}{l}\text { Argen } \\
\text { CIRSO }\end{array}$ & $\begin{array}{l}\text { na } \\
201\end{array}$ & & $\begin{array}{c}\text { Bolivia } \\
\text { NB-1225001-1 }\end{array}$ & $\begin{array}{c}\text { Brasil } \\
\text { BNT NBR } \\
6118: 2014\end{array}$ \\
\hline \multirow{4}{*}{$\begin{array}{l}\text { Penetración de } \\
\text { agua o succión } \\
\text { capilar. }\end{array}$} & \multirow{4}{*}{-} & \multirow{4}{*}{ - } & $\begin{array}{l}\text { Propiedad\Condición de } \\
\text { exposición }\end{array}$ & $\begin{array}{l}\text { Moderada } \\
\text { (Q1) }\end{array}$ & $\begin{array}{c}\text { Fuerte } \\
(\mathrm{Q} 2\end{array}$ & $\begin{array}{l}\text { Muy fuerte } \\
\text { (Q3) }\end{array}$ & \multirow{4}{*}{ - } & \multirow{4}{*}{ - } \\
\hline & & & \multirow{2}{*}{$\begin{array}{l}\text { Penetración de } \\
\text { agua }(\mathrm{mm})\end{array}$} & $\leq 50$ & $\leq 50$ & $\leq 50$ & & \\
\hline & & & & $\leq 30$ & $\leq 30$ & $\leq 30$ & & \\
\hline & & & $\begin{array}{l}\text { Succión capilar }(\mathrm{g} / \mathrm{m} 2 / \\
\mathrm{s} 0.5)\end{array}$ & 4.0 & 4.0 & 4.0 & & \\
\hline
\end{tabular}

Requerimientos para el concreto para las diferentes condiciones de exposición al agua

\begin{tabular}{|c|c|c|c|c|c|c|c|c|}
\hline Aspecto\País & $\begin{array}{l}\text { Perú } \\
\text { E.060 }\end{array}$ & & \multicolumn{2}{|c|}{$\begin{array}{c}\text { EEUU } \\
\text { ACI } 318-14\end{array}$} & $\begin{array}{c}\text { Argentina } \\
\text { CIRSOC } 201\end{array}$ & \multicolumn{2}{|l|}{$\begin{array}{c}\text { Bolivia } \\
\text { NB-1225001-1 }\end{array}$} & $\begin{array}{c}\text { Brasil } \\
\text { BNT NBR 6118:2014 }\end{array}$ \\
\hline Disposiciones generales & \multicolumn{2}{|l|}{-} & & & - & - & & $\begin{array}{l}\text { Lixiviación: Es el } \\
\text { mecanismo } \\
\text { responsable de disolver } \\
\text { y transportar los } \\
\text { compuestos hidratados } \\
\text { de la pasta de cemento } \\
\text { por acción de aguas } \\
\text { puras, carbónicas } \\
\text { agresivas, ácidas y } \\
\text { otras. Para prevenir } \\
\text { su ocurrencia, se } \\
\text { recomienda restringir } \\
\text { la fisuración, para } \\
\text { minimizar la } \\
\text { infiltración de agua, y } \\
\text { proteger las superficies } \\
\text { expuestas con productos } \\
\text { específicos, como los } \\
\text { hidrófugos. }\end{array}$ \\
\hline Relación máxima a/mc. & $\begin{array}{l}\text { Concreto que se } \\
\text { pretende tenga baja } \\
\text { permeabilidad en } \\
\text { exposición al agua. }\end{array}$ & 0.50 & W0 & 0.50 & \multirow[t]{3}{*}{ - } & $\begin{array}{c}\text { Hormigón que se pretende } \\
\text { tenga baja } \\
\text { permeabilidad en } \\
\text { exposición al agua. }\end{array}$ & 0.50 & - \\
\hline \multirow[b]{2}{*}{ f'c mínimo } & \multicolumn{2}{|l|}{${ }^{\star}$ En MPa } & $\frac{{ }^{*} \text { En }}{\text { W0 }}$ & $\frac{\text { pulg2 }}{2500}$ & & \multicolumn{2}{|l|}{${ }^{\star}$ En MPa } & \\
\hline & $\begin{array}{l}\text { Concreto que se } \\
\text { pretende tenga baja } \\
\text { permeabilidad en } \\
\text { exposición al agua. }\end{array}$ & 28 & W1 & 4000 & & $\begin{array}{l}\text { Hormigón que se pretende } \\
\text { tenga baja permeabilidad } \\
\text { en exposición al agua. }\end{array}$ & 28 & - \\
\hline
\end{tabular}


VÉRITAS Vol. 20 N¹ (2019) 65-81

Requerimientos para el concreto para la protección contra la carbonatación.

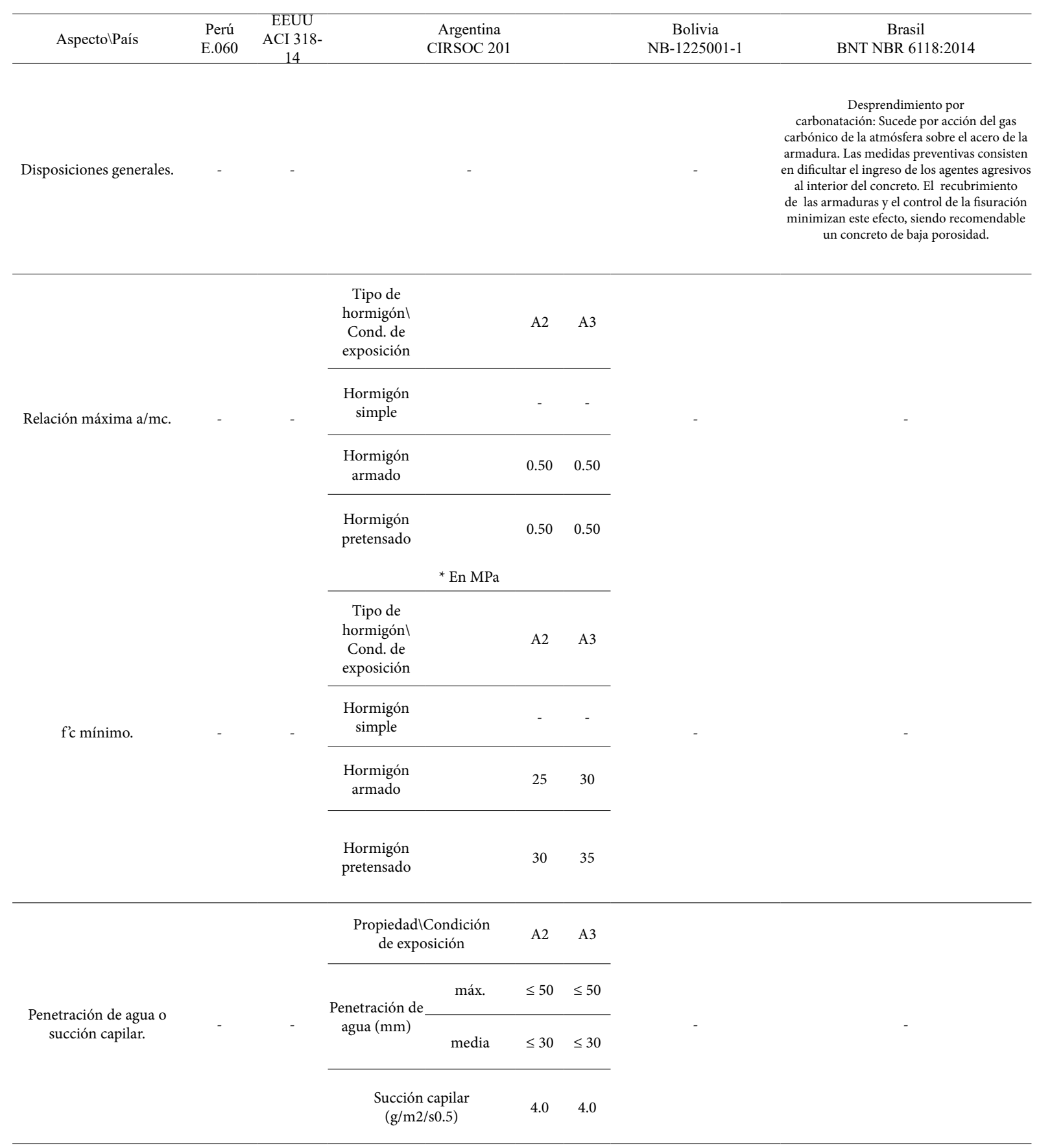


Dongo Gómez et al. / VÉRITAS Vol. 20 N¹ (2019) 65-81

\section{Requerimientos para el concreto para la protección del refuerzo contra la corrosión.}

\begin{tabular}{|c|c|c|c|c|c|}
\hline Aspecto\País & $\begin{array}{l}\text { Perú } \\
\text { E.060 }\end{array}$ & $\begin{array}{c}\text { EEUU } \\
\text { ACI } 318-14\end{array}$ & $\begin{array}{l}\text { Argentina } \\
\text { CIRSOC } 201\end{array}$ & $\begin{array}{c}\text { Bolivia } \\
\text { NB-1225001-1 }\end{array}$ & $\begin{array}{c}\text { Brasil } \\
\text { BNT NBR 6118:2014 }\end{array}$ \\
\hline $\begin{array}{l}\text { Disposiciones } \\
\text { generales. }\end{array}$ & $\begin{array}{l}\text { Para la protección contra } \\
\text { la corrosión del refuerzo } \\
\text { de acero en el concreto, las } \\
\text { concentraciones máximas de } \\
\text { iones cloruro solubles en agua } \\
\text { en el concreto endurecido a } \\
\text { edades que van de } 28 \text { a } 42 \text { días, } \\
\text { provenientes de los ingredientes } \\
\text { (incluyendo agua, agregados, } \\
\text { materiales cementantes y } \\
\text { aditivos) no deben exceder los } \\
\text { límites de la Tabla } 4.5 \text {. } \\
\text { Cuando se lleven a cabo ensayos } \\
\text { para determinar el contenido de } \\
\text { iones cloruro solubles en agua, } \\
\text { los procedimientos de ensayo } \\
\text { deben cumplir los requisitos } \\
\text { establecidos en la NTP } 334.148 .\end{array}$ & $\begin{array}{l}\text { Los límites de iones cloruro } \\
\text { deben ser aplicados a la Clases de } \\
\text { Exposición C0, C1 y C2. } \\
\text { Para el concreto no preesforzado, la } \\
\text { cantidad máxima de iones cloruro } \\
\text { solubles en agua, incorporados al } \\
\text { concreto, y medidos según la } \\
\text { ASTM C1218 a edades que van de } \\
28 \text { a } 42 \text { días, dependen del grado } \\
\text { de exposición proveniente de la } \\
\text { fuente externa de humedad y } \\
\text { cloruros. Para el concreto } \\
\text { preesforzado, se aplica el mismo } \\
\text { límite de } 0.06 \text { por ciento de iones } \\
\text { cloruro por peso de cemento } \\
\text { independientemente de la } \\
\text { exposición. }\end{array}$ & $\begin{array}{l}\text { Los contenidos máximos de } \\
\text { cloruros solubles en agua en el } \\
\text { hormigón endurecido, aportados } \\
\text { por todos los materiales componentes, } \\
\text { incluyendo los aditivos y eventualmente } \\
\text { adiciones minerales, deben ser iguales o } \\
\text { menores que los límites fijados más abajo. } \\
\text { Asimismo, elhormigón debe cumplir con } \\
\text { los requisitos de a/c, f'c y penetración o } \\
\text { succión capilar indicados más abajo. El } \\
\text { contenido de cloruros en el hormigón } \\
\text { endurecido se debe determinar a una } \\
\text { edad comprendida entre } 28 \text { y } 45 \text { días, } \\
\text { utilizando el método de la norma IRAM } \\
\text { 1857. En los estudios preliminares de los } \\
\text { materiales se puede estimar el contenido } \\
\text { total de cloruros que tendrá el hormigón } \\
\text { endurecido, como sumatoria del aporte } \\
\text { de sus materiales componentes en el } \\
\text { hormigón fresco. Si los valores estimados } \\
\text { son menores que los límites indicados } \\
\text { anteriormente, se puede considerar que } \\
\text { el contenido de cloruros del hormigón } \\
\text { endurecido, incorporados por los } \\
\text { materiales constituyentes, será menor que } \\
\text { el exigido por este Reglamento. }\end{array}$ & $\begin{array}{l}\text { Para la protección contra la } \\
\text { corrosión de la armadura } \\
\text { en el hormigón, las } \\
\text { concentraciones máximas de } \\
\text { iones cloruro acuosolubles } \\
\text { en hormigón endurecido } \\
\text { a edades que van de } 28 \text { a } \\
\text { 42 dís, provenientes de los } \\
\text { ingredientes, incluyendo } \\
\text { agua, agregados, materiales } \\
\text { cementantes y aditivos, no } \\
\text { deben exceder los límites } \\
\text { fijados más abajo. Cuando se } \\
\text { lleven a cabo ensayos para } \\
\text { determinar el contenido de } \\
\text { iones cloruro, solubles en } \\
\text { agua, los procedimientos de } \\
\text { ensayo deben cumplir los } \\
\text { requisitos establecidos en la } \\
\text { Norma ASTM C1218. } \\
\end{array}$ & $\begin{array}{c}\text { Desprendimiento por } \\
\text { acción de cloruros: } \\
\text { Consiste en la ruptura } \\
\text { local de la capa de } \\
\text { pasivación, causada } \\
\text { por un alto contenido } \\
\text { de iones de cloro. } \\
\text { e Las medidas } \\
\text { preventivas consisten } \\
\text { en dificultar el } \\
\text { ingreso de los agentes } \\
\text { agresivos al interior } \\
\text { del concreto. } \\
\text { El recubrimiento } \\
\text { de las armaduras } \\
\text { y el control de la } \\
\text { e fisuración minimizan } \\
\text { este efecto, siendo } \\
\text { recomendable el uso } \\
\text { de un concreto de } \\
\text { pequeña porosidad. } \\
\text { El uso de cemento } \\
\text { compuesto con } \\
\text { adición de escoria o } \\
\text { material puzolánico } \\
\text { es también } \\
\text { recomendable en estos } \\
\text { casos. }\end{array}$ \\
\hline
\end{tabular}

\begin{tabular}{|c|c|c|c|c|c|c|c|c|c|c|c|}
\hline \multirow{3}{*}{$\begin{array}{l}\text { Contenido máx. } \\
\text { de iones cloruro. }\end{array}$} & Tipo de elemento & $\begin{array}{l}\text { Contenido } \\
\text { máximo } \\
\text { de iones } \\
\text { de cloruro } \\
\text { solubles en } \\
\text { agua en el } \\
\text { concreto (\% } \\
\text { en peso del } \\
\text { cemento) }\end{array}$ & \multicolumn{3}{|c|}{$\begin{array}{l}\text { Contenido máximo de iones de cloruro } \\
\text { soluble en agua en el concreto, \% por } \\
\text { peso de cemento }\end{array}$} & Hormigón & $\begin{array}{l}\text { Condición de } \\
\text { exposición en } \\
\text { servicio }\end{array}$ & $\begin{array}{c}\text { Contenidos } \\
\text { máximos de ion } \\
\text { cloruro en el } \\
\text { hormigón } \\
\text { endurecido } \\
\text { (IRAM 1857) } \\
\\
\begin{array}{c}\text { \% en masa del } \\
\text { cemento }\end{array}\end{array}$ & \multirow{2}{*}{$\begin{array}{c}\begin{array}{c}\text { Tipo de } \\
\text { elemento }\end{array} \\
\text { Hormigón } \\
\text { pretensado }\end{array}$} & \multirow{2}{*}{$\begin{array}{c}\text { Contenido } \\
\text { máximo de } \\
\text { iones de } \\
\text { cloruro } \\
\text { solubles en } \\
\text { agua en el } \\
\text { hormigón, } \\
\% \text { peso de } \\
\text { cemento }\end{array}$} & \\
\hline & $\begin{array}{l}\text { Concreto } \\
\text { presforzado }\end{array}$ & 0.06 & $\begin{array}{l}\text { Condic. de } \\
\text { exposición|Tipo } \\
\text { de concreto }\end{array}$ & $\begin{array}{l}\text { Concreto no } \\
\text { preesforzado }\end{array}$ & $\begin{array}{l}\text { Concreto } \\
\text { preesforzado }\end{array}$ & Sin armar & $\begin{array}{l}\text { Cualquier } \\
\text { condición }\end{array}$ & 1.20 & & & \\
\hline & $\begin{array}{l}\text { Concreto armado } \\
\text { que en servicio } \\
\text { estará expuesto a } \\
\text { cloruros }\end{array}$ & 0.15 & $\mathrm{C} 0$ & 1.00 & 0.06 & $\begin{array}{l}\text { Armado, } \\
\text { con curado } \\
\text { normal }\end{array}$ & $\begin{array}{c}\begin{array}{c}\text { Medio } \\
\text { ambiente con } \\
\text { cloruros }\end{array} \\
\begin{array}{c}\text { Medio } \\
\text { ambiente sin } \\
\text { cloruros }\end{array}\end{array}$ & 0.15 & $\begin{array}{c}\text { Hormigón } \\
\text { armado que en } \\
\text { - servicio estará } \\
\text { expuesto a } \\
\text { cloruros }\end{array}$ & 0.15 & \\
\hline
\end{tabular}


VÉRITAS Vol. 20 N¹ (2019) 65-81

\begin{tabular}{|c|c|c|c|c|c|c|c|c|c|c|c|c|c|}
\hline Aspecto\País & \multicolumn{2}{|l|}{$\begin{array}{l}\text { Perú } \\
\text { E.060 }\end{array}$} & \multicolumn{3}{|c|}{$\begin{array}{c}\text { EEUU } \\
\text { ACI } 318-14\end{array}$} & \multicolumn{3}{|c|}{$\begin{array}{l}\text { Argentina } \\
\text { CIRSOC } 201\end{array}$} & & & \multicolumn{2}{|c|}{$\begin{array}{c}\text { Bolivia } \\
\text { NB-1225001-1 }\end{array}$} & \multirow{3}{*}{$\begin{array}{c}\text { Brasil } \\
\text { BNT NBR } \\
\text { 6118:2014 } \\
\end{array}$} \\
\hline \multirow{2}{*}{$\begin{array}{c}\text { Contenido } \\
\text { máx. de iones } \\
\text { cloruro. }\end{array}$} & $\begin{array}{c}\text { Concreto } \\
\text { armado que en } \\
\text { servicio estará } \\
\text { seco o protegido } \\
\text { contra la } \\
\text { humedad }\end{array}$ & 1.00 & $\mathrm{C} 1$ & 0.30 & 0.06 & $\begin{array}{l}\text { Armado, con } \\
\text { curado a vapor }\end{array}$ & $\begin{array}{l}\text { Cualquier } \\
\text { condición }\end{array}$ & 0.10 & & & $\begin{array}{l}\text { Hormigón } \\
\text { armado que en } \\
\text { servicio estará } \\
\text { seco o protegido } \\
\text { contra la } \\
\text { humedad }\end{array}$ & 1.00 & \\
\hline & $\begin{array}{c}\text { Otras } \\
\text { construcciones de } \\
\text { concreto armado }\end{array}$ & 0.30 & $\mathrm{C} 2$ & 0.15 & 0.06 & Pretensado & $\begin{array}{l}\text { Cualquier } \\
\text { condición }\end{array}$ & 0.06 & & & $\begin{array}{c}\text { Otras } \\
\text { construccio nes } \\
\text { de hormigón } \\
\text { armado }\end{array}$ & 0.30 & \\
\hline \multirow{4}{*}{$\begin{array}{l}\text { Relación } \\
\text { máxima a/ } \\
\text { mc. }\end{array}$} & & & & & & $\begin{array}{c}\text { Tipo de } \\
\text { hormigón } \backslash \text { Cond. } \\
\text { de exposición }\end{array}$ & CL & M1 & M2 & M3 & \multirow{4}{*}{\multicolumn{2}{|c|}{-}} & \multirow{4}{*}{-} \\
\hline & - & & & - & & Hormigón simple & 0.45 & - & 0.45 & 0.40 & & & \\
\hline & & & & & & Hormigón armado & 0.45 & 0.50 & 0.45 & 0.40 & & & \\
\hline & & & & & & $\begin{array}{l}\text { Hormigón } \\
\text { pretensado }\end{array}$ & 0.45 & 0.50 & 0.45 & 0.40 & & & \\
\hline \multirow{5}{*}{ f'c mínimo. } & & & \multirow{5}{*}{\multicolumn{3}{|c|}{-}} & \multicolumn{5}{|c|}{${ }^{*}$ En MPa } & \multirow{5}{*}{ - } & & \multirow{5}{*}{ - } \\
\hline & & & & & & $\begin{array}{c}\text { Tipo de } \\
\text { hormigón } \backslash \text { Cond. } \\
\text { de exposición }\end{array}$ & CL & M1 & M2 & M3 & & & \\
\hline & - & & & & & Hormigón simple & 30 & - & 30 & 0.45 & & & \\
\hline & & & & & & Hormigón armado & 35 & 30 & 35 & 0.40 & & & \\
\hline & & & & & & $\begin{array}{l}\text { Hormigón } \\
\text { pretensado }\end{array}$ & 40 & 35 & 40 & 0.40 & & & \\
\hline
\end{tabular}


Dongo Gómez et al. / VÉRITAS Vol. 20 N¹ (2019) 65-81

\begin{tabular}{|c|c|c|c|c|c|c|c|c|c|}
\hline Aspecto \País & $\begin{array}{l}\text { Perú } \\
\text { E.060 }\end{array}$ & $\begin{array}{c}\text { EEUU } \\
\text { ACI } 318-14\end{array}$ & & $\begin{array}{r}\text { Arg } \\
\text { CIRS }\end{array}$ & ina & & & $\begin{array}{c}\text { Bolivia } \\
\text { NB-1225001-1 }\end{array}$ & $\begin{array}{c}\text { Brasil } \\
\text { BNT NBR } \\
\text { 6118:2014 }\end{array}$ \\
\hline \multirow{4}{*}{$\begin{array}{l}\text { Penetración de agua o } \\
\text { succión capilar. }\end{array}$} & \multirow{4}{*}{ - } & \multirow{4}{*}{-} & $\begin{array}{l}\text { Propiedad\Cond } \\
\text { ición de exposición }\end{array}$ & CL & M1 & M2 & M3 & \multirow{4}{*}{ - } & \multirow{4}{*}{ - } \\
\hline & & & \multirow{2}{*}{$\begin{array}{c}\text { Penetra } \\
\text { ción de } \\
\text { agua }(\mathrm{mm})\end{array}$} & $\leq 50$ & $\leq 50$ & $\leq 50$ & $\leq 50$ & & \\
\hline & & & & $\leq 30$ & $\leq 30$ & $\leq 30$ & $\leq 30$ & & \\
\hline & & & $\begin{array}{l}\text { Succión capilar } \\
(\mathrm{g} / \mathrm{m} 2 / \mathrm{s} 0.5)\end{array}$ & 4.0 & 4.0 & 4.0 & 4.0 & & \\
\hline
\end{tabular}

Requerimientos para el concreto para las diferentes condiciones de exposición a agresividad ambiental y/o generales.

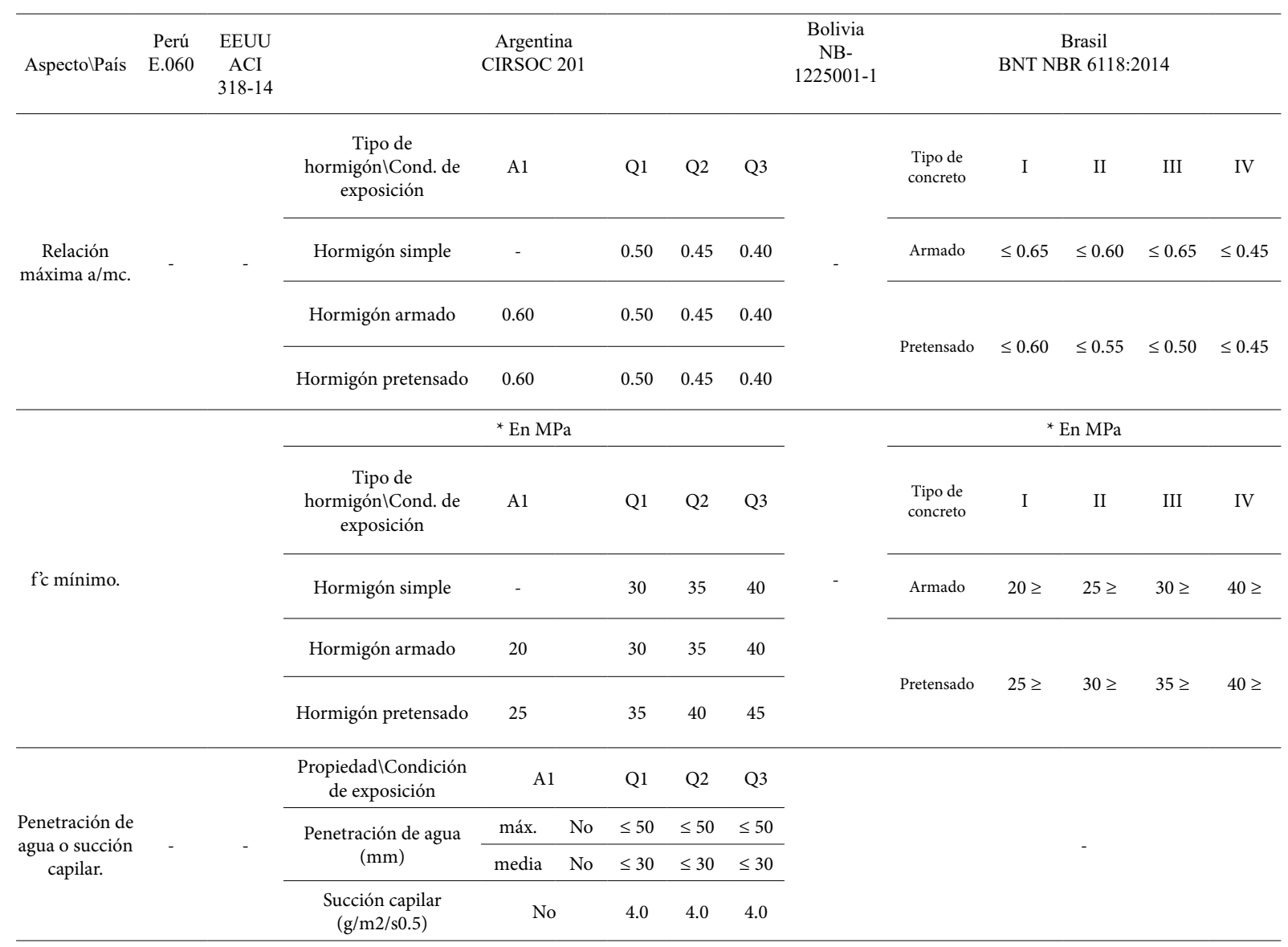


VÉRITAS Vol. 20 N¹ (2019) 65-81

\begin{tabular}{|c|c|c|c|c|c|c|c|c|c|c|}
\hline Aspecto $\backslash$ País & $\begin{array}{l}\text { Perú } \\
\text { E.060 }\end{array}$ & $\begin{array}{c}\text { EEUU } \\
\text { ACI 318-14 }\end{array}$ & $\begin{array}{c}\text { Argentina } \\
\text { CIRSOC } \\
201\end{array}$ & $\begin{array}{c}\text { Bolivia } \\
\text { NB-1225001-1 }\end{array}$ & \multicolumn{6}{|c|}{$\begin{array}{c}\text { Brasil } \\
\text { BNT NBR 6118:2014 }\end{array}$} \\
\hline & & & & & \multirow{3}{*}{ Tipo de estructura } & \multirow{3}{*}{ Componente o elemento } & \multicolumn{4}{|c|}{ Clase de agresividad } \\
\hline & & & & & & & I & II & III & IV \\
\hline & & & & & & & $\begin{array}{c}\mathrm{Recu} \\
\mathrm{mm} \\
\mathrm{ej}\end{array}$ & $\begin{array}{l}\text { rimi } \\
\text { ara u } \\
\text { ucić }\end{array}$ & $\begin{array}{l}\text { to no } \\
\Delta \mathrm{c}=\end{array}$ & $\begin{array}{l}\text { inal en } \\
\text { acia de } \\
\mathrm{nm}\end{array}$ \\
\hline & & & & & \multirow{3}{*}{ Concreto armado } & Losas & 20 & 25 & 35 & 45 \\
\hline \multirow[t]{4}{*}{$\begin{array}{c}\text { Recubrimiento } \\
\text { nominal. }\end{array}$} & - & - & - & - & & Viga/columna & 25 & 30 & 40 & 50 \\
\hline & & & & & & $\begin{array}{l}\text { Elementos estructurales en contacto } \\
\text { con el suelo }\end{array}$ & \multicolumn{2}{|c|}{30} & 40 & 50 \\
\hline & & & & & \multirow{2}{*}{$\begin{array}{l}\text { Concreto } \\
\text { pretensado }\end{array}$} & Losa & 25 & 30 & 40 & 50 \\
\hline & & & & & & Viga/columna & 30 & 35 & 45 & 55 \\
\hline
\end{tabular}

\section{Análisis crítico}

Se tiene en cuenta que las normas latinoamericanas toman como referencia la norma estadounidense ACI 318, por lo que se encontrará información semejante.

\section{Nomenclatura y clasificación}

La nomenclatura es diferente en las normas de los distintos países, sin embargo, se encuentra similitud en las clasificaciones y conceptos.

\section{Exposición a congelamiento y deshielo}

La norma estadounidense, peruana y boliviana exponen la misma clasificación, cuatro niveles de exposición, uno de éstos considera la acción de productos químicos y sales descongelantes; la norma argentina solo contempla en su clasificación la acción u omisión de sales descongelantes, mientras que la brasilera no toma en cuenta esta condición.

\section{Exposición a sulfatos}

La norma estadounidense, peruana, boliviana y argentina contemplan los mismos rangos de cantidades de sulfato en concretos, el último presenta una variación en unidades. La norma brasilera no presenta datos acerca de esta condición.

\section{Contacto con el agua}

La norma estadounidense clasifica este tipo de exposición en dos secciones, cuando el concreto se encuentra en contacto con el agua y cuando no presenta contacto alguno, este último no presenta datos posteriormente por lo que las normas peruana y boliviana decidieron omitirlo. La norma argentina y brasilera no presentan datos acerca de esta condición.

\section{Riesgo de corrosión}

Solo las normas estadounidense y argentina presentan información sobre la condición mencionada. Argentina presenta una clasificación desarrollada con cantidades y parámetros exactos referidos a ataques de carbonatación y cloruros, mientras que la norma estadounidense tiene una clasificación general.

\section{Agresividad ambiental y/o general}

La norma argentina y brasilera presentan la misma clasificación, siendo la norma argentina más detallada que la brasilera. La norma estadounidense, peruana y boliviana no presentan información.

\section{Requerimientos para el concreto para las diferentes condiciones de exposición a congelamiento y deshielo.}

Todas las normas presentan información excepto la brasilera, por lo que la siguiente información está referida solo a las normas estadounidense, peruana, argentina $y$ boliviana.

Disposiciones generales: Son las mismas y nos indican que los concretos expuestos a congelamiento y deshielo deben contener aire incorporado.

Relación agua/material cementante: Considerara los mismos valores a excepción de la norma estadounidense que nos proporciona un dato extra referido a una exposición moderada.

Resistencia a la compresión mínima: Considera los mismos valores a excepción de la norma estadounidense que nos proporciona dos datos extra referidos a concretos que no presentan exposición y los que tienen una exposición moderada a congelamiento y deshielo (en unidades americanas). 
Contenido total de aire: Considera los mismos valores, la norma estadounidense presenta unidades americanas, la norma argentina no presenta datos para un tamaño máximo nominal de $9.5 \mathrm{~mm}$ y presenta rangos de valores en lugar de datos exactos.

Porcentaje máximo del total de material cementante en peso: Solo las normas estadounidense, peruana y boliviana presentan datos (los mismos).

Penetración de agua o succión capilar: La norma argentina es la única que presenta datos sobre este parámetro.

\section{Requerimientos para el concreto para las diferentes con-} diciones de exposición a sulfatos

Todas las normas presentan información excepto la brasilera, ésta solo presentará una breve reseña en disposiciones generales, por lo que la siguiente información está referida solo a las normas estadounidense, peruana, argentina y boliviana.

Disposiciones generales: La norma brasilera solo considera el uso de cementos especiales mencionados en la norma ABNT NBR 5737. Por otro lado, la norma peruana y boliviana comentan que los concretos deben seguir las condiciones dispuestas posteriormente.

Tipo de cemento según el grado de exposición: Las distintas normas presentan datos similares, la norma estadounidense subdivide la clasificación según lo mencionado en las ASTM C1157, C150 y C595 normas referidas al cemento hidráulico, cemento Portland y cementos adicionados. La norma argentina nos recomienda revisar la norma IRAM 50001:2000 en la cual tenemos una clasificación a detalle de los tipos de cemento y sus características.

Relación máxima agua/material cementante: Todas las normas contemplan los mismos valores excepto la argentina que recomienda un valor más conservador cuando se tiene una exposición muy fuerte a sulfatos.

Resistencia a la compresión mínima: En esta sección los valores varían, la norma peruana y boliviana tienen los mismos datos con una sola coincidencia con la norma estadounidense. La norma argentina por otra parte, considera valores más conservadores.

Aditivo de cloruro de calcio: La norma argentina no presenta datos sobre este aditivo, sin embargo, para las demás no está permitida en exposiciones a sulfatos severas y muy severas.

Penetración de agua o succión capilar: La única norma que menciona este parámetro es la argentina.

Requerimientos para el concreto para las diferentes condiciones de exposición al agua

En este acápite solo las normas peruana, estadounidense y boliviana presentan parámetros de relación agua cemento máxima y resistencia a la compresión mínima; la norma brasilera presenta una breve explicación sobre lixiviación y algunas recomendaciones.
Requerimientos para el concreto para la protección contra la carbonatación

La norma brasilera proporciona una breve explicación sobre la carbonatación de estructuras de concreto y recomienda el uso de concretos de baja porosidad. La norma argentina es la única que nos brinda parámetros como relación máxima de agua/material cementante, resistencia a la compresión mínima y profundidad de penetración máxima, que nos ayuda a prevenir este problema.

\section{Requerimientos para el concreto para la protección del} refuerzo contra la corrosión

Todas las normas presentan información excepto la brasilera, esta solo presentará una breve reseña en disposiciones generales, por lo que la siguiente información está referida solo a las normas estadounidense, peruana, argentina y boliviana.

Disposiciones generales: Las distintas normas exponen que el concreto debe tener una concentración máxima de iones cloruro aportada por todos sus componentes, esta concentración será calculada entre los días 28 y 42 desde el inicio del fraguado.

Contenido máximo de iones cloruro: Todas las normas contemplan los mismos valores, la norma argentina presenta datos extra como valores para concreto sin refuerzo de acero y para concreto armado curado a vapor.

La norma argentina es la única que nos brinda parámetros sobre relación máxima de agua/material cementante, resistencia a la compresión mínima y profundidad de penetración máxima, que nos ayuda a prevenir este problema.

Requerimientos para el concreto para las diferentes condiciones de exposición a agresividad ambiental y/o generales

Las únicas normas que presentan información en este acápite son la argentina y la brasilera.

Máxima relación agua cemento y resistencia a la compresión mínima: Ambas normas presentan valores similares; la norma argentina presenta valores más conservadores.

Penetración de agua o succión capilar: La norma argentina es la única que presenta datos sobre este parámetro.

Recubrimiento nominal: La norma brasilera es la única que presenta datos sobre este parámetro.

\section{CONCLUSIONES}

La norma peruana es una adaptación de la norma estadounidense. La norma boliviana es una adaptación de la norma estadounidense.

La norma argentina es una adaptación de la norma estadounidense con la diferencia que considera valores más conservadores.

No se encuentra ninguna relación entre las normas ACI 318-14 (estadounidense) y BNT NBR 6118:2014 (brasilera).

La norma brasilera solo presenta datos relacionados a la agresividad ambiental.

La norma argentina es la única que menciona valores sobre penetración máxima y succión capilar de agua.

La norma argentina a pesar de ser la más antigua, contiene 
mayor cantidad de parámetros mínimos a ser considerados.

La norma brasilera es la única que habla sobre recubrimientos del concreto en condiciones especiales.

\section{RECOMENDACIONES}

Se recomienda que la norma peruana incorpore el ensayo de profundidad de penetración de agua.

Se recomienda que la norma peruana incorpore valores límite referidos a profundidad de penetración y succión capilar del agua.

Se recomienda realizar una comparativa experimental considerando parámetros mínimos de la norma argentina y la norma peruana; el propósito será comprobar si es necesario considerar valores conservadores como los de la norma argentina o si los datos propuestos por nuestra norma son competentes.

Se recomienda realizar una investigación experimental, la cual proponga valores límite de coeficiente de permeabilidad para cada caso, esto nos proporcionará un mejor control de la permeabilidad en el concreto expuesto.

\section{REFERENCIAS BIBLIOGRÁFICAS}

1. Reglamento Nacional de Edificaciones. (2009). Norma E.060 - Concreto armado.

2. Servicio Nacional de Capacitación para la Industria de la Construcción - SENCICO. 318.

3. ACI 318 -14. (2014). Requisitos de Reglamento para concreto estructural. Comité ACI

4. CIRSOC 201. (2005). Reglamento argentino de estructuras de hormigón. INTI. NB-1225001-1. (2014). Norma boliviana de hormigón estructural. IBNORCA.

5. BNT NBR 6118:2014. (2014). Projeto de estruturas de concreto - procedimento. Asociación brasilera de normas técnicas. 